\title{
ANALYSIS OF URBAN INDEXES AND PARAMETERS FACILITATED BY PARAMETERIZATION: creation of a database for architectural study in Chapecó/SC
}

\author{
Luana Peroza Piaia \\ Unochapecó | Brasil | luanapiaia@unochapeco.edu.br \\ Carla Cristina Secchi \\ Unochapecó | Brasil | cah_secchi@unochapeco.edu.br \\ Paola Avila \\ Unochapecó | Brasil | paola.avila@unochapeco.edu.br \\ Ana Luisa Scariot \\ Unochapecó | Brasil | anascariot@unochapeco.edu.br
}

\begin{abstract}
Parameterization has shown potential in creating architectural projects and verification steps. The objective is to develop a parametric and generative tool, containing the urban parameters of the Master Plan of a municipality, to assist in the phase of field study. The model is developed with the aid of Revit software and Dynamo plug-in. The results converge to a tool where users enter the lot's dimensions and zoning, and it applies the other parameters. It is possible to analyze the constructive potential quickly, avoiding errors. The parameterization process is emphasized, encouraging the user to apply new methodologies in early project stages.
\end{abstract}

Keywords: Parameterization; Design Process; Urban Indexes; Constructive Potential.

\section{INTRODUÇÃO}

A evolução de técnicas digitais transformou o processo de projeto na construção, e desencadeou a necessidade de aprimoramento dos métodos de ensino de Arquitetura e Urbanismo. Para Silva, Mussi, Silva e Zardo (2018) as tecnologias têm o intuito de conceber um cenário que possibilita o compartilhamento de dados entre projetistas, em um só local. Nestas circunstâncias, destaca-se a eficácia da tecnologia BIM (Building Information Model), com modelos tridimensionais conectados e dados precisos e inteligentes, contribuindo para o rápido encontro de informações em projetos (Silva et al., 2018). Atualmente, um dos maiores desafios para profissionais e estudantes da área é integrar o uso de informações digitais, de modo a aliar parametrização e interoperabilidade ao longo do processo. Neste sentido, ressalta-se a importância da utilização do BIM durante todo o ciclo de vida do projeto, pois nele encontram-se ferramentas primordiais a respeito de características físicas e operacionais do modelo, desde orçamentação e dados relativos ao conforto ambiental, até Modelagem Paramétrica (MP) (Silva et al., 2018).

Os modelos parametrizados são compostos por um conjunto de dados e regras, caracterizando uma geometria integrada, na qual qualquer alteração realizada transforma as demais de maneira conectada (Basto \& Lordsleem Junior, 2016). Segundo Florio (2009), a parametrização tem por finalidade facilitar o processo de projeto, modificando este de forma simples, e seu uso tem ganhado mais espaço, devido à eficácia no desenvolvimento de geometrias de elementos construtivos. O design paramétrico, associado a softwares de programação, altera o processo de concessão do produto, sendo o algoritmo responsável por calcular e configurar as modificações propostas, gerando economia de tempo e custo na concepção do produto (Silva, Silva, Barbieri, \& Bruscatto, 2016).

Os softwares de arquitetura devem possibilitar ao usuário gerar e manipular geometrias, simples e complexas, de modo a interpretá-las e organizá-las no processo. Com isso, pode-se visualizar de forma nítida os impactos e limitações existentes, auxiliando o projetista na tomada de decisões (Silva et al., 2018). Esta funcionalidade é viabilizada pela Modelagem Paramétrica, que constitui uma representação computacional com condicionantes fixas e variáveis, a partir de parâmetros e regras que promovem a alteração e adaptação de características, conforme necessidade do projetista (Romcy \& Cardoso, 2019). Este processo tem como atributo o desenvolvimento de respostas emergentes com soluções diversas, porém coerentes, enfatizando o potencial generativo. Assim, muda-se o conceito de "fazer a forma" (making of form), para "encontrar a forma" (finding of form) (Romcy \& Cardoso, 2019).

O surgimento da MP promoveu aproximação entre arquitetura e ferramentas de desenho, que por sua vez, alteraram significativamente 0 modo de representar projetos de maneira digital. Antes, as formas se baseavam em geometrias explícitas - claras e estanques -, agora, tem-se a representação de modelos geométricos alteráveis (Silva \& Amorim, 2010). Deste modo, na 
Modelagem Paramétrica, os parâmetros são vistos como essenciais para o projeto, e não a forma gerada, como é visto no processo tradicional (Silva \& Amorim, 2010).

A diferença entre um modelo paramétrico e um modelo tradicional de representação de desenho digital, está na facilidade de se fazer alterações ao longo do processo de projeto. A partir de uma combinação de regras, pode-se criar infinitas possibilidades, automatizando um processo que, manualmente, levaria muito mais tempo (Silva et al., 2016). Quando há mudança de um valor, toda a forma se adapta a ele, sem que sejam necessárias intervenções manuais (Ruschel \& Bizello, 2011). Com isso, há a possibilidade de criar, testar e incrementar diferentes propostas, partindo apenas da alteração de determinado parâmetro (Silva \& Amorim, 2010).

Com a utilização da MP, aperfeiçoa-se o elo entre projetista e projeto, melhorando o entendimento geral do processo. A constante relação entre desenho, ferramentas e materialização possibilita a formação de um ciclo, no qual as potencialidades podem ser questionadas diversas vezes, analisando e alterando qualquer parâmetro, implicando nas decisões e resultados de projetos (Arcari, Pereira, Costacurta Junior \& Mansano, 2015).

A parametrização possui conceitos bem definidos, porém, cada software transcreve os parâmetros a partir de seu próprio modelo (Acari et al., 2015). Esta diversidade não interfere nos princípios concretos da Modelagem Paramétrica, mas abre caminho para discussões e questionamentos acerca do que se pode realizar por meio dessa tecnologia (Acari et al., 2015).

$\mathrm{Na}$ arquitetura, podem ser desenvolvidos parâmetros e regras que permitam a mudança de componentes de edificações, apenas com alterações numéricas, descartando o retrabalho nos projetos arquitetônicos (Mororó, Romcy, Cardoso, \& Barros Neto, 2016). Apesar de ser utilizada como ferramenta de desenho, destacando a representação e visualização dos projetos, a MP tem enorme potencial como método de verificação, impulsionando a criação de novas formas dentro do ambiente digital (Silva \& Amorim, 2010).

Paralelo a isso, e regulamentado pela Lei Federal $\mathrm{n} .^{0}$ $10.257 / 2001$, determina o Estatuto da Cidade, que visa a criação de normas que atendam a ordem pública, segurança, uso dos lotes urbanos em favor do bem coletivo e social, na busca da melhora na qualidade de vida dos cidadãos. Estabelece também, a criação de instrumentos de políticas urbanas, neste caso, destaca-se os Planos Diretores que auxiliam no ordenamento territorial, definem o poder e responsabilidade sobre o uso, ocupação e parcelamento do solo, por meio de índices urbanísticos. Estes dados estabelecem parâmetros de ocupação do solo, em diferentes territórios do município a que se refere, computados sobre as dimensões de cada lote (LEI N. ${ }^{\circ}$ 10.257, DE 10 DE JULHO DE 2001)

Considerando a potencialidade da MP na verificação de projetos, aponta-se como relevante sua implementação na etapa de estudo do terreno, no processo de projeto arquitetônico, em meio acadêmico e profissional. Um modelo parametrizado acelera o processo, permitindo variedade de formas e rápida visualização (Oliveira \& Fabricio, 2011), uma vez que, agilidade e diminuição de equívocos são os grandes ganhos da prática. O objetivo da pesquisa é o desenvolvimento de uma ferramenta paramétrica e generativa, contendo os índices e parâmetros urbanísticos determinados pelo Plano Diretor do Município de Chapecó, estado de Santa Catarina, Brasil, como forma de auxiliar na fase inicial de estudo do terreno e compreender seu potencial construtivo.

\section{METODOLOGIA}

A presente pesquisa possui abordagem qualitativa, objetivo exploratório e explicativo, além de finalidade e método experimentais. A abordagem qualitativa está atrelada ao maior destaque ao instrumento estudado, assim como ações que pretendem caracterizar, entender e expor a investigação realizada (Silveira \& Córdova, 2009). O objetivo exploratório, de acordo com Gil (2017), visa estreitar a relação entre o problema e os pesquisadores, por meio de levantamentos, coleta de dados e pesquisa sobre o tema estudado, neste caso, o Plano Diretor de Chapecó/SC. Com relação ao objetivo explicativo, este caracteriza-se por verificar e esclarecer os aspectos que influenciam para que os fatos ocorram, sendo um estudo mais excessivo e profundo (GIL, 2017).

Baseando-se em Gil (2017), esta pesquisa assume como finalidade o desenvolvimento experimental, caracterizado pela sistematização, em que o enfoque é o desenvolvimento de novos materiais, neste caso, um código computacional paramétrico e generativo. O método é classificado como uma experimentação, que de acordo com Gil (2017) constitui-se na determinação de um instrumento de investigação e da seleção de seus fatores influentes, estabelecendo por último como será o seu controle para a ocorrência dos fenômenos. Neste método os pesquisadores são sujeitos ativos, manipulando e controlando os fatores para a conclusão da investigação (Gil, 2017).

Esta pesquisa é baseada na análise do formato de concepção e viabilidade de aplicação de um modelo parametrizado para observação de potencial construtivo, com índices estabelecidos pelo Plano Diretor da cidade de Chapecó - SC.

A base de dados paramétricos foi desenvolvida por meio da metodologia BIM, utilizando o software Revit da Autodesk associado ao plug-in Dynamo. Este módulo de extensão é um programa que opera sobre o Design Script, uma linguagem de programação paramétrica que dispõe aos utilizadores componentes de criação de sistemas próprios de manipulação BIM, além de trabalhar com rotinas de trabalho que não necessitam ser refeitas (Silva et al., 2018).

O desenvolvimento da base de dados paramétricos da cidade de Chapecó, efetuou-se em duas etapas, que convergem para os resultados alcançados pela pesquisa, são elas:

a) Estudo da legislação municipal: Plano Diretor de Chapecó/SC, Lei complementar $N^{0} 541$, de 26 de novembro de 2014.

b) Concepção do código paramétrico e generativo, que manipule os índices e parâmetros urbanísticos.

\section{PLANO DIRETOR DE CHAPECÓ - PDC}

Chapecó situa-se na região extremo Oeste do estado de Santa Catarina - Brasil, possuindo uma população 
estimada de 224.013 habitantes, densidade demográfica de $293,15 \mathrm{hab} / \mathrm{km}^{2}$, área da extensão territorial de 624,846 $\mathrm{km}^{2}$, e em relação a topografia urbana, tem-se como altitude mínima $234 \mathrm{~m}$ e altitude máxima $1.002 \mathrm{~m}$, apresentando então desníveis moderados (IBGE, 2020).

Planos Diretores são de fundamental importância no eficiente ordenamento da expansão territorial de um município. Estes documentos estabelecem zoneamentos específicos passíveis de abrigar equipamentos residenciais, industriais, comerciais e de serviço, com base em condicionantes naturais, históricas e de mobilidade, constituindo as chamadas Zonas de Ocupação (Chapecó 2014). Cada município é responsável por estabelecer as diretrizes de sua expansão territorial, por meio de estudos aprofundados e profissionais aptos à realização deste planejamento.

Índices Urbanísticos representam os limites territoriais em relação a ocupação urbana, e os parâmetros são definidos no Plano Diretor subdividindo-se em unidades territoriais, cada qual possuindo suas especificidades, de acordo com a localização na cidade. No desenvolvimento do código deste estudo, com foco no município de Chapecó, foram consideradas as referências urbanísticas estabelecidas em seu Plano Diretor, aprovado pela Lei Complementar $\mathrm{n}^{\circ}$ 541 , de 26 de novembro de 2014. Os dados descritos a seguir, e utilizados como aporte desta pesquisa, partem do estabelecido no Anexo III-A desta legislação, referentes às principais Unidades Territoriais do município, pertencentes à Macrozona Urbana (Figura 1). Neste anexo estão descritos todos os índices necessários para o ordenamento territorial, bem como os parâmetros levados em consideração na hora da realização de qualquer tipo de projeto.

Descreve-se abaixo os principais índices e parâmetros utilizados para a realização do código paramétrico e generativo:

Coeficiente de Aproveitamento (CA): é o índice urbanístico que define o potencial construtivo do lote na unidade territorial em que está inserido, resultado do produto entre este e a área do lote, diferenciado em CA Mínimo, caracterizando possível subutilização de um imóvel; CA Básico, referente ao permitido para a unidade; e CA Máximo, que corresponde ao Básico acrescido da outorga onerosa do direito de construir máxima (Chapecó, 2014).

Taxa de Ocupação (TO): corresponde ao índice urbanístico que limita a máxima projeção ortogonal possível da área construída, em percentual aplicado sobre a área do lote, diferenciando-a quanto à Base e Torre (Chapecó, 2014).

Recuos: o recuo de ajardinamento é a distância entre a projeção ortogonal da edificação e o alinhamento predial do imóvel, tendo como objetivo a reserva de áreas para ampliação visual, iluminação e ventilação de espaços públicos, podendo ser utilizado para futuro alargamento viário (Chapecó, 2014).

Afastamentos: necessários para a qualificação ambiental das áreas construídas, em especial a garantia de parâmetros mínimos de ventilação e iluminação natural, obtidos pela projeção ortogonal das laterais e do fundo da edificação sobre as divisas do lote (Chapecó, 2014).

Número de Pavimentos: o limite da altura das edificações é definido pelo número máximo de pavimentos indicado na Tabela Anexo III-A ou conforme o Coeficiente de Aproveitamento, variando de acordo com a Unidade Territorial que se trata. $O$ cálculo utilizando o CA se refere à razão entre o potencial construtivo e a área de um pavimento (Chapecó, 2014).

Taxa de Permeabilidade (TP): corresponde à proporção entre a área permeável do lote e sua área total, não devendo ser coberta ou receber pavimentação, exceto do tipo permeável (Chapecó, 2014).

Índice Verde: já este corresponde ao percentual de área do lote que deverá obrigatoriamente possuir cobertura vegetal (Chapecó, 2014).

\begin{tabular}{|c|c|c|c|c|c|c|c|c|c|c|c|c|c|c|}
\hline \multicolumn{13}{|c|}{$\begin{array}{l}\text { INDICES E PARÂMETROS URBANISTICOS } \\
\text { MACROZONA URBANA - MU }\end{array}$} & \multicolumn{2}{|c|}{ Anexo III-A } \\
\hline Unidade Territorial & \begin{tabular}{|c|}
$\begin{array}{r}\text { Lote } \\
\text { min. }\end{array}$ \\
$\mathrm{m} 2$
\end{tabular} & \multicolumn{2}{|c|}{ Testada min. } & \multicolumn{3}{|c|}{$\begin{array}{l}\text { Coeficiente de } \\
\text { Aproveitamento (CA) }\end{array}$} & \multicolumn{2}{|c|}{$\begin{array}{l}\text { Taxa de } \\
\text { Ocupaçäo (TO }\end{array}$} & $\begin{array}{l}\text { Recuo min. } \\
\text { (m) }\end{array}$ & $\begin{array}{c}\begin{array}{c}\text { Afastamento } \\
\text { min. }\end{array} \\
\text { (m) }\end{array}$ & $\begin{array}{l}\begin{array}{l}\text { Indice } \\
\text { Verde }\end{array} \\
\text { (\$) }\end{array}$ & $\begin{array}{l}\text { Número } \\
\text { putos }\end{array}$ & \begin{tabular}{|c|}
$\begin{array}{c}\text { Taxa de } \\
\text { Permeabilidade (TP) }\end{array}$ \\
(\%)
\end{tabular} & $\begin{array}{c}\begin{array}{r}\text { Dimensobes } \\
\text { maximimas } \\
\text { quadras }\end{array} \\
\text { (m) }\end{array}$ \\
\hline \begin{tabular}{|l} 
Area Urbana Central - AUC \\
\end{tabular} & 360 & 15 & 12 & 0,2 & 9 & 10,2 & 90 & 60 & 0 (b) & (a) & 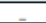 & Conf. CA & 5 & 192 \\
\hline Area Urbana de Transiçäo - AUT & 360 & 15 & 12 & 0,2 & 5 & 6 & 80 & 60 & $4(\mathrm{~b})$ & (a) & & Conf. CA & 10 & 192 \\
\hline Unidade de Moradia - UM & 360 & 15 & 12 & 0,1 & 1,8 & 2,4 & 60 & 60 & $4(\mathrm{~b})$ & (a) & 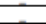 & $\frac{4}{4}$ & 20 & 220 \\
\hline \begin{tabular}{|l|} 
Unidade Funcional de Descentralizaça do \\
Desenvolvimento da Bacia - UFDOB
\end{tabular} & 450 & 15 & 15 & 0,15 & 2,6 & 3,6 & 70 & 60 & $4(b)$ & (a) & - & 8 & 20 & 195 \\
\hline $\begin{array}{l}\text { Unidade Funcional de Descentralizaçăo do } \\
\text { Desenvolvimento Nivel 1- UFDO1 }\end{array}$ & 450 & 15 & 15 & 0,2 & 5 & 6 & 70 & 60 & $4(\mathrm{~b})$ & (a) & - & Conf. CA & 20 & 195 \\
\hline $\begin{array}{l}\text { Unidade Funcional de Descentralizaça do do } \\
\text { Desenvolvimento Nivel 2-UFDO2 }\end{array}$ & 450 & 15 & 15 & 0,2 & 5 & 6 & 70 & 60 & $0(b)$ & (a) & - & Conf. CA & 20 & 195 \\
\hline $\begin{array}{l}\text { Unidade Funcional de Requalificaçäo Territorial - } \\
\text { UFRT }\end{array}$ & 4.000 & 40 & 40 & - & 0,4 & 0,6 & 50 & so & 10 (b) & 4 & $20(\mathrm{~s})$ & 6 & 20 & - \\
\hline Área Especial de Interesse Ambiental - AEIA (c) & 4.000 & 40 & 40 & - & 0,8 & 1,2 & 20 & 20 & 10 (b) & 4 & - & Conf. ca & 20 & 320 \\
\hline $\begin{array}{l}\text { Area Especial de Interesse Ambiental e Moradia. } \\
\text { ALIAM }\end{array}$ & 4.000 & 40 & 40 & - & 2,6 & 5 & 30 & 30 & 10 (b)(d) & 4 & - & Conf. CA & 20 & 320 \\
\hline Área Especial de interesse institucional- AEIT & - & - & - & - & 3,6 & - & 70 & 60 & 4 (b) & varísvel & - & 8 & 20 & - \\
\hline Unidade Industrial Consolidada - UIC & - & - & - & - & 1 & 1,4 & 60 & 60 & $4(b)$ & 4 & - & 6 & 20 & - \\
\hline Unidade Industrial Consolidada da Bacia - UICB & - & - & - & - & 0,8 & - & 60 & 60 & $8(b)$ & 4 & - & 6 & 20 & - \\
\hline Área de Parque Cientifico e Tecnologico - APCT & 600 & 15 & 15 & - & 1,8 & - & 40 & 40 & $4(b)$ & 2 & - & Conf. $\mathrm{cA}$ & 20 & - \\
\hline $\begin{array}{l}\text { Unidade Funcional de Desenvolvimento de Serviços } \\
\text { de Saúde - UFDSs }\end{array}$ & 360 & 15 & 12 & - & 3,6 & - & 70 & 60 & $4(\mathrm{~b})$ & (a) & - & 8 & 20 & - \\
\hline
\end{tabular}

Figura 1: Tabela Anexo III-A. Fonte: Chapecó (2014). 
A Tabela do Anexo III-A também define dimensões mínimas para área e testada de lotes (esquina e meio de quadra), bem como dimensões máximas de quadras.

\section{DESENVOLVIMENTO DA PARAMÉTRICA E GENERATIVA}

O código paramétrico e generativo proposto neste estudo visa atuar sobre os parâmetros iniciais de partido arquitetônico. Propõe-se uma concepção que permita o reconhecimento dos dados de entrada de um lote e seu zoneamento territorial, tendo como resultado uma projeção volumétrica do potencial construtivo, baseando-se nos cinco índices urbanísticos descritos.

Para abastecer a ferramenta com os dados do Plano Diretor apresentados na Figura 1, inicialmente foi necessário transcrevê-los em uma planilha no software Excel, sendo as Unidades Territoriais representadas pelas linhas e seus respectivos parâmetros em colunas (Figura 3).

Isto posto, iniciou-se o desenvolvimento da ferramenta, dividida em oito grupos de componentes, determinados no plug-in Dynamo como "conjuntos de nós personalizados", separados por funcionalidade. A Figura 2 representa 0 modelo paramétrico e generativo criado, com seus grupos distintos por cores.

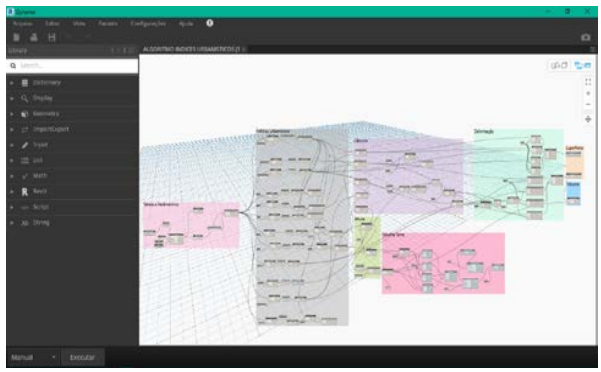

Figura 2: Ferramenta paramétrica e generativa criada. Fonte: os autores (2020)
O primeiro conjunto de nós, nomeado como "Tabela e Parâmetros" (Figura 4), corresponde à inserção da planilha criada no software Excel e que forma a base para a evolução do processo. Neste grupo, têm-se a separação de nós específicos para leitura do arquivo inserido, possibilitando a diferenciação dos índices urbanísticos e seus dados. Deve-se entrar com as dimensões do lote em estudo e a seleção de seu respectivo zoneamento. Automaticamente o algoritmo interpreta a numeração deste na planilha e atualiza os demais nós com os parâmetros correspondentes.

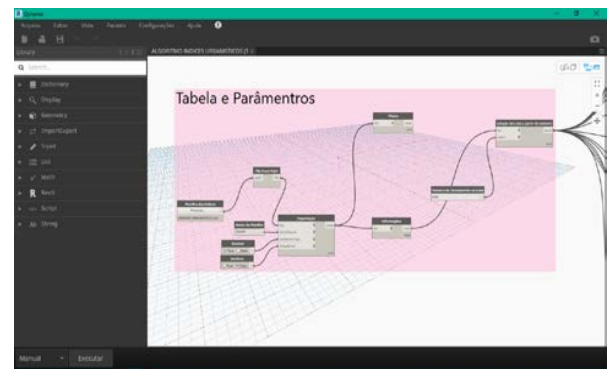

Figura 4: Primeiro conjunto de nós: "Tabela e Parâmetros". Fonte: os autores (2020).

Em seguida, foi criado o segundo grupo, denominado "Índices Urbanísticos" (Figura 5), no qual parâmetros oriundos da planilha foram desmembrados e correspondem, cada um, a um nó. Este conjunto norteia a ocupação do lote e corresponde aos parâmetros iniciais da projeção do volume do potencial construtivo. Nesta etapa, a análise da Taxa de Permeabilidade e do Índice Verde se mostrou irrelevante, pois atendendo aos limites estabelecidos para a Taxa de Ocupação, automaticamente estes também serão atendidos. Tratam também, de definições projetuais específicas, como definição de materiais, não envolvendo a etapa projetual correspondente à ferramenta.

\begin{tabular}{|c|c|c|c|c|c|c|c|c|c|c|c|c|c|c|c|c|}
\hline & * & . & s & - & $=$ & , & a & " & ' & , & * & . & н & n &. & . \\
\hline & UNIDADE TERRITORIAL & $\begin{array}{l}\text { Lote } \\
\text { min. } \\
\left(\mathrm{m}^{2}\right)\end{array}$ & $\begin{array}{l}\text { Test } \\
\text { Esqui } \\
\text { Meio }\end{array}$ & $\begin{array}{l}\text { min. } \\
\text { la }(m) \\
\text { de } Q . \\
\text { ) }\end{array}$ & $\begin{array}{l}\text { Coefi } \\
\text { Mín. }\end{array}$ & $\begin{array}{l}\text { iciente } \\
\text { pr. (CA } \\
\text { Báx. } \\
\text { Mán }\end{array}$ & $\begin{array}{l}\text { te de } \\
\text { A) } \\
\text { Básc. }\end{array}$ & $\begin{array}{l}\text { Taxa } \\
\text { Ocup } \\
\text { B (\%) }\end{array}$ & $\begin{array}{l}\text { a de } \\
\text { pação } \\
\text { T (\%) }\end{array}$ & $\begin{array}{l}\text { Recuo } \\
\text { Mín. }\end{array}$ & $\begin{array}{l}\text { Afasta. } \\
\text { Min. } \\
\text { (m) }\end{array}$ & $\begin{array}{c}\text { indice } \\
\text { Verde } \\
(\%)\end{array}$ & $\begin{array}{l}\text { Númer } \\
\text { o de } \\
\text { Putos. }\end{array}$ & $\begin{array}{c}\text { Taxa de } \\
\text { Permeabilida } \\
\text { de (TP) (\%) }\end{array}$ & $\begin{array}{c}\text { Dimensões } \\
\text { Máx. } \\
\text { Quadras }\end{array}$ & \\
\hline$i$ & Area Urbana Centra-AUC & 360 & 15 & 12 & 0,2 & 9 & 10,2 & 90 & 60 & 0 & - & - & CA & 5 & 192 & \\
\hline , & Área Urbana de Transicão-AUT & 360 & 15 & 12 & 0.2 & 5 & 6 & 80 & 60 & 4 & - & - & CA & 10 & 192 & \\
\hline . & Unidade de Moradia - UM & 360 & 15 & 12 & 0,1 & 1,8 & 2,4 & 60 & 60 & 4 & - & - & 4 & 20 & 220 & \\
\hline : & Unidade Ambiental de Moradia - UAM & 360 & 15 & 12 & 0,1 & 1,8 & 2,4 & 60 & 60 & 4 & - & - & CA & 20 & 192 & \\
\hline : & $\begin{array}{l}\text { Unidade de Conservação Ambiental e } \\
\text { Moradia-UCAM }\end{array}$ & 2.400 & 30 & 30 & - & 0,1 & 0,2 & 10 & 10 & 8 & 5 & 30 & 4 & 60 & 240 & \\
\hline & $\begin{array}{l}\text { Unidade Funcional de Descentralização do } \\
\text { Desenvolvimento da Bacia - UFDDB }\end{array}$ & 450 & 15 & 15 & 0,15 & 2,6 & 3,6 & 70 & 60 & 4 & - & - & 8 & 20 & 195 & \\
\hline ' & $\begin{array}{l}\text { Unidade Funcional de Descentralização do } \\
\text { Desenvolvimento Nivel 1- UFDD1 }\end{array}$ & 450 & 15 & 15 & 0,2 & 5 & 6 & 70 & 60 & 4 & - & - & CA & 20 & 195 & \\
\hline , & $\begin{array}{l}\text { Unidade Funcional de Descentralização do } \\
\text { Desenvolvimento Nivel } 2 \text { - UFDD2 }\end{array}$ & 450 & 15 & 15 & 0,2 & 5 & 6 & 70 & 60 & 0 & - & - & CA & 20 & 195 & \\
\hline " & $\begin{array}{l}\text { Unidade Funcional de Requalificação } \\
\text { Territorial - UFRT }\end{array}$ & 4.000 & 40 & 40 & - & 0,4 & 0,6 & 50 & 50 & 10 & 4 & 20 & 6 & 20 & - & \\
\hline & $\begin{array}{l}\text { Unidade Funcional de Atividades } \\
\text { Agroindustriais e de Serviços - UFAAS }\end{array}$ & 2.400 & 30 & 30 & - & 0,6 & 1,2 & 60 & 60 & 10 & 4 & 20 & 6 & 20 & 360 & \\
\hline 18 & $\begin{array}{l}\text { Unidade Funcional de Produção Industrial } \\
\text { Prioritária - UFPIP }\end{array}$ & 2.400 & 30 & 30 & - & 0,6 & 1,2 & 60 & 60 & 10 & 4 & 20 & 6 & 20 & 360 & \\
\hline 19 & Área Especial de Interesse Ambiental - AEIA & 4.000 & 40 & 40 & - & 0,8 & 1,2 & 20 & 20 & 10 & 4 & - & CA & 20 & 320 & \\
\hline 14 & $\begin{array}{l}\text { Área Especial de Interesse Ambiental e } \\
\text { Moradia - AEIAM }\end{array}$ & 4.000 & 40 & 40 & $\cdot$ & 2,6 & 5 & 30 & 30 & 10 & 4 & $\cdot$ & CA & 20 & 320 & \\
\hline 18 & Área Especial de Interesse Institucional - & & & & - & 3,6 & - & 70 & 60 & 4 & - & - & 8 & 20 & - & \\
\hline 15 & Unidade Industrial Consolidada - UIC & & & & - & 1 & 1,4 & 60 & 60 & 4 & 4 & - & 6 & 20 & - & \\
\hline 18 & Unidade Industrial Consolidada da Bacia - & & & & - & 0,8 & - & 60 & 60 & 8 & 4 & - & 6 & 20 & - & \\
\hline 1 & Área de Parque Cientifico e Tecnologico- & 600 & 15 & 15 & - & 1,8 & - & 40 & 40 & 4 & 2 & - & $C A$ & 20 & - & \\
\hline & $\begin{array}{l}\text { Unidade Funcional de Desenvolvimento de } \\
\text { Serviços de Saúde - UFDSS }\end{array}$ & 360 & 15 & 12 & - & 3,6 & - & 70 & 60 & 4 & - & - & 8 & 20 & - & \\
\hline
\end{tabular}

Figura 3: Planilha Excel dos índices e parâmetros das unidades territoriais de Chapecó. Fonte: Chapecó (2014). Adaptado pelos autores (2020). 


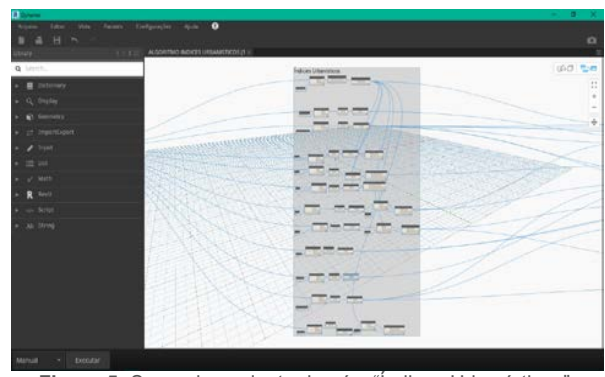

Figura 5: Segundo conjunto de nós: "Indices Urbanísticos".

Fonte: os autores (2020).

O terceiro conjunto de nós denomina-se "Cálculos" (Figura 6) ordena as operações e resultados a partir dos parâmetros definidos no grupo anterior. Nele os nós operam sobre as dimensões do lote, resultando na projeção do volume, respeitando Recuos, Afastamentos e Taxas de Ocupação. Além disso, determina a máxima área construída possível, partindo das três possibilidades de Coeficiente de Aproveitamento. Deve-se definir qual pretende-se analisar inicialmente, contudo esta seleção pode ser alterada a qualquer momento, sendo todas passíveis de análise, de forma individual.

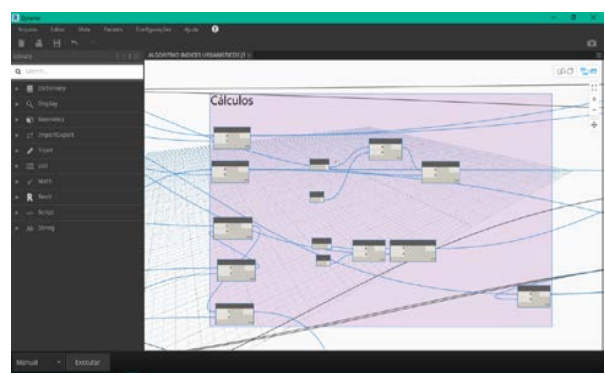

Figura 6: Terceiro conjunto de nós: "Cálculo"'. Fonte: os autores (2020).

Para originar a projeção referente ao potencial construtivo, criou-se o quarto conjunto de nós, denominado "Delimitações" (Figura 7). Baseia-se na criação dos pontos relacionados às proporções do lote e ocupação da construção, separadamente. Criam-se coordenadas que delimitam as superfícies para posterior extrusão. É importante ressaltar que, por trabalhar com apenas 4 pontos e interpretar somente duas dimensões do terreno, a análise do potencial construtivo pode ser realizada somente sobre condições retangulares ou quadradas.

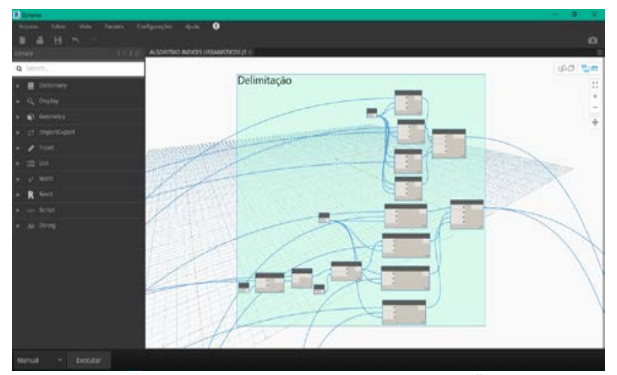

Figura 7: Quarto conjunto de nós: "Delimitações". Fonte: os autores (2020).
Delimitada a área do lote e a ocupação da edificação, o quinto grupo, denominado "Superfícies" (Figura 8), une os pontos e forma o plano sólido, tanto do terreno quanto da construção.

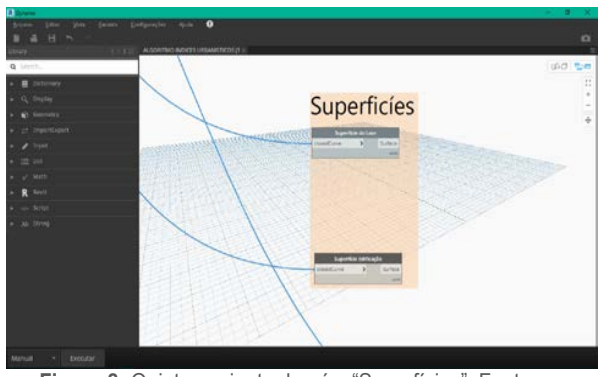

Figura 8: Quinto conjunto de nós: "Superfícies". Fonte: os autores (2020)

Obtendo o plano, o sexto grupo, denominado "Altura" (Figura 9), representa a altura do volume, com foco apenas na multiplicação do número de pavimentos. Para a concepção desta ferramenta, foi definida altura de piso a piso igual a 3 metros. Nesta etapa, existem dois nós que executam projeções diferentes, um para os zoneamentos que definem o número máximo de pavimentos com um numeral, e outro para os que variam de acordo com o cálculo do CA. No último caso, há um nó que interpreta a leitura dos 14,40 metros máximos de altura da Base, definida pelo Plano Diretor de Chapecó, e o restante distribui para a Torre.

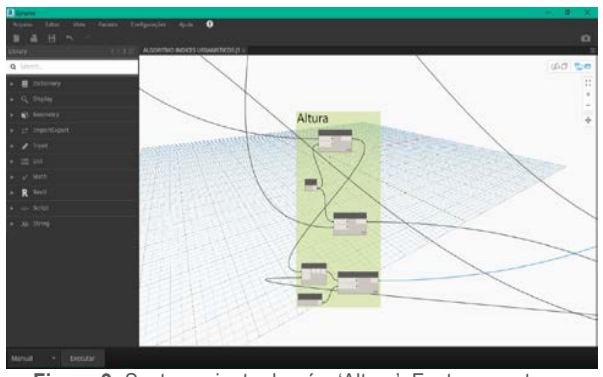

Figura 9: Sexto conjunto de nós: 'Altura'. Fonte: os autores (2020).

Assim, conectou-se o quinto e sexto conjunto de nós ao sétimo, intitulado "Volume" (Figura 10), que permite a extrusão da superfície criada seguindo as definições da altura máxima, gerando o sólido que representa a proporção do espaço construído.

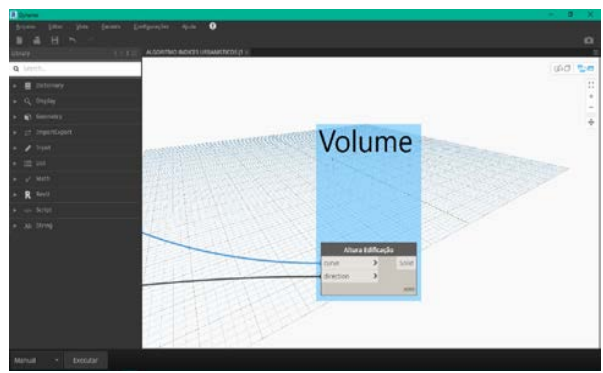

Figura 10: Sétimo conjunto de nós: 'Volume'. Fonte: os autores (2020). 
Nos casos em que há variação de Base e Torre, até o sétimo conjunto de nós desenvolve-se a volumetria apenas da Base. Para possibilitar a criação da Torre, foi necessária a inserção do oitavo conjunto de nós, usado somente nos casos de Unidades Territoriais que preveem esta diferenciação.

O grupo de nós "Volume Torre" (Figura 11) realiza a delimitação e criação desta superfície conforme definido no conjunto dos "Cálculos", e realiza a extrusão da resposta recebida pela conexão ao conjunto "Altura". Este grupo baseia-se em pontos com coordenadas acima da Base, resultando no volume da Torre. Sempre que se tratar desta diferenciação da volumetria, o oitavo grupo deve ser conectado manualmente à ferramenta.

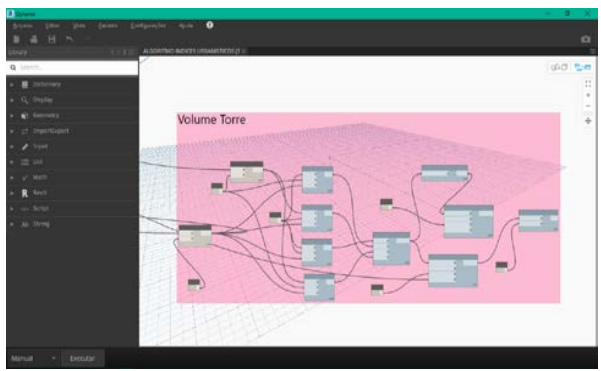

Figura 11: Oitavo conjunto de nós: 'Volume Torre'. Fonte: os autores (2020)

\section{RESULTADOS E DISCUSSÕES}

Aspirando exibir a funcionalidade do sistema, foram escolhidos três zoneamentos, com parâmetros bastante distintos, para validar sua utilização, são eles: Unidade de Moradia (UM), Unidade de Conservação Ambiental e Moradia (UCAM) e Área Urbana Central (AUC). Para efeitos de estudo, foram utilizadas as dimensões de lotes mínimos de cada unidade e seu CA Básico. As demais características particulares são descritas a seguir.

Unidade de Moradia (UM): é o zoneamento destinado ao uso residencial qualificado, além de possíveis atividades econômicas de pequeno porte, garantindo a preservação ambiental local e a qualidade de vida dos residentes (Chapecó, 2014). Caracteriza-se por lote mínimo de 360 $\mathrm{m}^{2}$ e testada mínima de 12 m; CA Básico 1,8; TO da Base e Torre 60\%; Recuo mínimo 4 m; Afastamento mínimo 5\% da testada do lote ou $0,85 \mathrm{~m}$, o que resultar maior; Número máximo de quatro pavimentos; e Taxa de Permeabilidade $20 \%$. A projeção do volume do potencial construtivo desta unidade é representada na Figura 12.

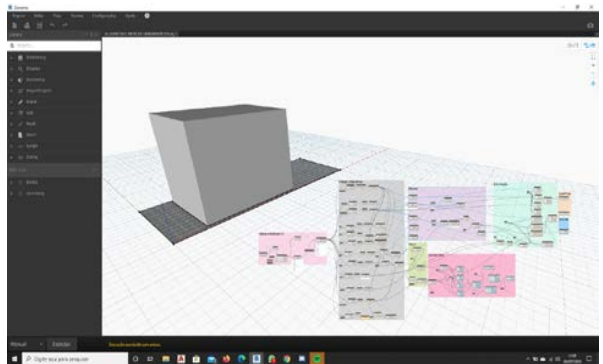

Figura 12: Projeção do volume do potencial construtivo da unidade territorial UM. Fonte: os autores (2020).
Unidade de Conservação Ambiental e Moradia (UCAM): Este zoneamento está localizado na porção norte da barragem de armazenamento de água potável do Município de Chapecó, sendo destinado a sítio e chácaras, bem como atividades recreativas e de lazer, devendo a prioridade ser da preservação ambiental natural e uso residencial qualificado, extinguindo qualquer possibilidade de cunho industrial (Chapecó, 2014). Também é previsto a utilização de $30 \%$ da área do lote para preservação ambiental por meio de espécies nativas (Chapecó, 2014). É constituída por lote mínimo de $2.400 \mathrm{~m}^{2}$ e testada mínima de 30m; CA Básico 0,1; TO da Base e Torre 10\%; Recuo mínimo 8m; Afastamento mínimo 5 m; Índice Verde $30 \%$; Número máximo de quatro pavimentos; e Taxa de Permeabilidade $60 \%$. A projeção do volume do potencial construtivo da UCAM é representada na Figura 13.

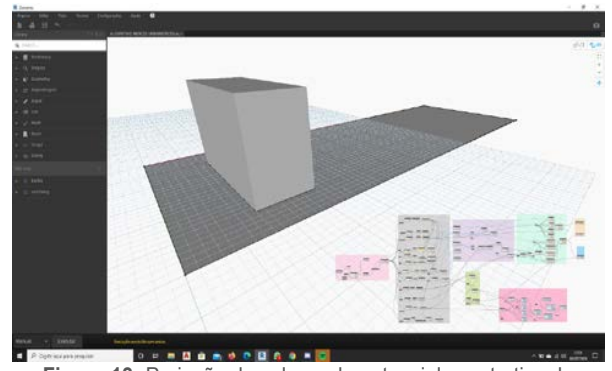

Figura 13: Projeção do volume do potencial construtivo da unidade territorial UCAM. Fonte: os autores (2020).

Área Urbana Central (AUC): abriga as áreas urbanas centrais do município de Chapecó, as quais são providas de uma melhor infraestrutura, serviços públicos e oportunidades, em decorrência da urbanização altamente densificada e das atividades econômicas ali desenvolvidas (Chapecó, 2014). Rege a promoção do equilibro entre estas áreas residenciais e comerciais, além da qualidade da espacialização e uso da infraestrutura pública (Chapecó, 2014). Caracterizada por lote mínimo de $360 \mathrm{~m}^{2}$ e testada mínima de 12 m; CA Básico 9,0; TO da Base $90 \%$ e da Torre $60 \%$; não exige Recuos; Afastamento mínimo $5 \%$ da testada do lote ou $0,85 \mathrm{~m}$, o que resultar maior; Número de Pavimentos conforme o CA; e Taxa de Permeabilidade $5 \%$. A projeção do volume do potencial construtivo da AUC é representada na Figura 14.

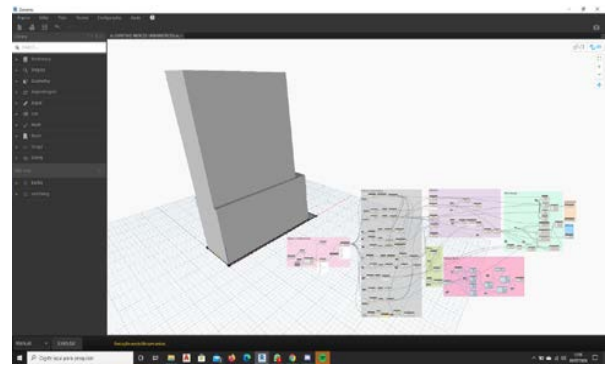

Figura 14: Projeção do volume do potencial construtivo da unidade territorial AUC. Fonte: os autores (2020).

Observa-se que a Unidade de Moradia e Unidade de Conservação Ambiental e Moradia possuem Taxas de Ocupação da Base e Torre iguais, assim como o número máximo de até quatro pavimentos. Portanto, o código paramétrico generativo opera sem necessidade de conexão do oitavo conjunto de nós ('Volume Torre'). Em 
ambos os casos foi necessário somente inserir o tamanho do lote e selecionar a Unidade Territorial correspondente, sendo o restante gerado pelo sistema, que projeta o potencial construtivo, levando em consideração todos os demais parâmetros.

No caso da AUC, fez-se necessária a conexão do oitavo conjunto de nós ao sistema, para gerar a diferenciação do volume da Torre. É preciso alterar, no segundo conjunto, os parâmetros relacionados ao potencial construtivo de Base e Torre, além do Número de Pavimentos conforme o CA. Feito isso, o dispositivo interpreta as adaptações e executa o volume em conformidade.

Com isso, o código converge para um modelo abastecido com os Índices Urbanísticos do Município de Chapecó, pertencentes ao Anexo III-A, no qual o usuário deve introduzir a configuração espacial do lote e selecionar o zoneamento desejado. Os resultados seguem o princípio de organização volumétrica coerente aos parâmetros a que correspondem, gerando automaticamente um partido volumétrico do potencial construtivo para um determinado sítio em uma Unidade Territorial pré-selecionada, representando os limites estabelecidos na legislação. Vale destacar que os estudos iniciais deste código visam a realização em superfícies topográficas planas, posteriormente pretende-se adequar o algoritmo para que atenda terrenos com qualquer desnível.

\section{CONCLUSÃO}

Após a concepção e prática da ferramenta, pôde-se constatar que a Modelagem Paramétrica é uma tecnologia digital de grande importância na interpretação das análises dos Índices Urbanísticos. Apesar da construção do algoritmo ter se mostrado complexa, as alterações dos parâmetros são feitas de forma fácil, rápida e assertiva. A concepção do sistema baseado na simulação dos padrões construtivos possibilitou precisa análise dos dados, bem como comparação entre potenciais de diferentes lotes.

O desenvolvimento e as respostas encontradas com a criação deste processo de parametrização alcançaram de maneira inicial o objetivo, que visa auxiliar o entendimento da legislação em vigência no Município de Chapecó. Contudo, a configuração atual do código não permite a análise de formatos orgânicos de volumetria, como também não responde de forma efetiva a configurações de lotes diferentes de retângulos ou quadrados. Outro fator a ser resolvido é a necessidade de conexão manual do oitavo grupo de nós ao sistema, quando forem necessárias análises de Torre. Estes fatores estão sendo estudados e novas possibilidades sendo consideradas, bem como a criação de um tutorial de aplicação da ferramenta, para que seu uso possa ser executado por terceiros.

Dentre as contribuições geradas a partir do desenvolvimento deste estudo, tem-se a possibilidade de análise do potencial construtivo de lotes, de forma rápida e facilitada, reduzindo o tempo gasto com cálculos e tentativas manuais, explorando possibilidades, evitando erros de limites de projeto e facilitando a conferência destes índices. Outro fator relevante é a popularização do processo de parametrização, instigando o usuário a aplicar novas metodologias ainda na fase de estudo do terreno.

É de fundamental importância para o profissional e estudante de Arquitetura e Urbanismo o entendimento dos parâmetros descritos nas legislações municipais. Além de serem instrumentos de política urbana, são responsáveis pelo ordenamento do desenvolvimento territorial, interferindo diretamente no processo de projeto.

O emprego da Modelagem Paramétrica, por meio de softwares como Revit, associado ao plug-in Dynamo, induz à procura das novas tecnologias computacionais pelos profissionais, assim como, a criação de métodos diferenciados que simplifiquem e estimulem as informações e ações projetuais. Na concepção da metodologia do ensino de Arquitetura e Urbanismo, o uso de tais ferramentas digitais estimula o aluno a inovar no processo de projeto, buscando alternativas eficientes de redução do tempo e exatidão de parâmetros. Estas ações influenciam significativamente no desenvolvimento de funções cognitivas dos acadêmicos, possibilitando clara percepção de cada fase do processo.

A parametrização é expressa como agente modificador na formação do partido arquitetônico, juntamente com os padrões estabelecidos pela legislação. Sua função tornase fundamental para a clareza de tais índices, podendo aprimorar as didáticas em sala de aula e no mercado de trabalho, facilitando 0 entendimento destas pelos acadêmicos e profissionais, visando acelerar o processo de conhecimento das condicionantes do local.

\section{AGRADECIMENTOS}

À UNOCHAPECÓ, ao Estado de Santa Catarina e ao Programa de Bolsas Universitárias de Santa Catarina (UNIEDU), pelo apoio financeiro firmado ao acreditarem no projeto de pesquisa em questão.

\section{REFERÊNCIAS}

Arcari, E. D. A., Pereira, A. T. C., Costacurta Junior, R., Mansano, I. (2015). Interoperabilidade: Um desafio para o Processo de Modelagem Parametrizada de Detalhes Arquitetônicos e sua Materialização. Paper presented at the SIGraDi, Florianópolis, Brasil.

Basto, P. E. D. A., Lordsleem Junior, A. C. (2016). O ensino de BIM em curso de graduação em engenharia civil em uma universidade dos EUA: estudo de caso. Ambiente Construído, 45 61.

Florio, W. (2009). Modelagem Paramétrica em Arquitetura: Estratégias para Materializar Formas Complexas. Paper presented at the SIGraDi, São Paulo, Brasil.

Gil, A. C. (2017). Como elaborar projetos de pesquisa. (Vol. 6 ). Rio de Janeiro: Atlas.

Instituto Brasileiro de Geografia e Estatística (IBGE). Censo Brasileiro de 2020. Rio de Janeiro: 2020

Lei Complementar $N^{\circ} 541$, de 26 de novembro de 2014. (2014). APROVA O PLANO DIRETOR DE CHAPECÓ - PDC. Chapecó. Recuperado em 18 julho 2020, de https://leismunicipais.com.br/plano-diretor-chapeco-sc.

Lei n. ${ }^{\circ} 10.257$, de 10 de julho de 2001. (2001). Regulamenta os Art. 182 e 183 da Constituição Federal, estabelece diretrizes gerais da política urbana e dá outras providências. Senado Federal, Brasília. Recuperado em 18 julho 2020, de https://www2.camara.leg.br/legin/fed/lei/2001/lei-10257-10-julho2001-327901-publicacaooriginal-1-pl.html

Mororó, M. S. D. M., Romcy, N. M. e S., Cardoso, D. R., Barros Neto, J. D. P. (2016). Proposta paramétrica para projetos sustentáveis de Habitação de Interesse Social em ambiente BIM. Ambiente Construído, 27-44.

Oliveira, M. R.D., Fabricio, M. M. (2011). Projeto Paramétrico e Prototipagem Rápida: Casos em Instituições Internacionais. In E. 
d. Oficina de Textos (Ed.), O processo de projeto em arquitetura da teoria à tecnologia.

Romcy, N. M. e S.; Cardoso, D. R. (2019). A introdução da abordagem paramétrica no ensino de projeto arquitetônico: relato de uma experiência. PARC Pesquisa em Arquitetura e Construção.

Ruschel, R. C., Bizello, S. A. (2011). Avaliação de Sistemas CAD livres. In E. d. Oficina de Textos (Ed.), O processo de projeto em arquitetura da teoria à tecnologia.

Silva, J. L.; Mussi, A. Q.; Silva, T. L.; Zardo, P. (2018). Designers of the XXI century: BIM software programming and the development of new competencies. Paper presented at the SIGraDi, São Paulo, Brasil.

Silva, F. P. D., Silva, L. S. D., Barbieri, G., Bruscato, U. M. (2016). O uso do conceito paramétrico aplicado a uma inovação no mobiliário urbano: estudo de caso bicicletário. Paper presented at the SIGraDi, São Paulo, Brasil.

Silva, R. C. D., Amorim, L. M. D. E. (2010). Da arquitetura paramétrica ao urbanismo paramétrico. Paper presented at the SIGraDi, Bogotá, Colômbia.

Silveira, D. T., \& Córdova, F. P. (2009). UNIDADE 2 - A PESQUISA CIENTÍFICA. In E. d. UFRGS (Ed.), Métodos de pesquisa (pp. 31-42) 